\title{
Desafios para a área da linguagem
}

\author{
Maria Teresa Tedesco Vilardo Abreu ${ }^{a}$
}

\section{Resumo}

Considerando os índices alarmantes em relação ao desenvolvimento da proficiência dos estudantes brasileiros, que exemplificam o fracasso educacional do Brasil, propomo-nos a uma reflexão acerca da importância da linguagem para a formação básica do estudante. Postula-se que dominar a linguagem significa estar mais preparado para interagir com outras pessoas, o que implica ter a possibilidade de influenciar no modo de agir e pensar do outro. $\mathrm{Na}$ perspectiva de base (sócio)cognitivista, acredita-se em um processo educacional que interpreta os indivíduos como sujeitos sociais, que não são prontos, mas se (re) constroem discursivamente. Por isso, a escola tem função primordial de ampliar o domínio linguístico do aluno, para que seja capaz de participar ativamente da sociedade em que está inserido. A consequência dessa concepção é o entendimento de que a diversidade textual em suas diferentes organizações e finalidades se constitui no grande objeto de estudos da sala de aula para o desenvolvimento da leitura, da escrita e da análise discursiva. A linguag em, nessa perspectiva, é o grande patrimônio linguístico que deve ser explorado, não apenas, nas aulas de lingua materna, mas em todas as disciplinas, incentivando o caráter científico, tributo da área dos estudos linguísticos.

Palavras-chave: Linguagem. Ensino. Diversidade textual. Desenvolvimento de proficências.

Recebido em novembro de 2013. Aprovado em marco de 2014.

\footnotetext{
${ }^{a}$ UERJ - Universidade do Estado do Rio de Janeiro, Instituto de Letras. Rio de Janeiro, Rio de Janeiro, BR.
} teresatedesco2011@hotmail.com 


\section{Contextualização}

Não há quem não tenha conhecimento do fato de que os índices brasileiros de repetência estão diretamente ligados à questão do desenvolvimento da proficiência dos estudantes nos diferentes anos de escolaridade do ensino básico. A escola brasileira não tem cumprido sua função de ensinar a ler, no sentido lato do termo e, também, não tem cumprido a função no que tange ao ensino da escrita. Na verdade, não se trata de uma dificuldade para a alfabetização, ou seja, de um mero domínio do código somente, mas de garantia do uso eficaz da língua em todos os níveis de situações comunicativas nas quais nos envolvemos na vida. É fato que, nos últimos vinte anos, passamos de 1,66 milhões para 7,04 milhões de matrículas nos cursos superiores, mas quase $40 \%$ de nossos universitários sabem ler e escrever de forma insignificante; poucos têm conhecimentos matemáticos necessários para participarem de um bom curso nas áreas de ciências ou engenharia. É raro o aluno ser capaz de dominar um idioma como segunda língua. Finge-se ser possível dar um salto à universidade sem passar pela educação de base.

Comemoramos ter passado de 36 milhões, em 1994, para 50 milhões de matriculados na Educação Básica, em 2014, sem dar atenção ao fato de termos 13 milhões de adultos brasileiros analfabetos; 54,5 milhões de brasileiros com mais de 25 anos não terminaram o Ensino Fundamental e 70 milhões não terminaram o Ensino Médio. Finge-se que os alunos matriculados estão estudando, quando se sabe que passam temporadas sem aula, dentre vários motivos, por falta de professores ou por ausência de uma educação profícua, que sirva, de fato, para fazer a diferença na vida de cada aluno, por este ter aprendido o que é básico no denominado ensino formal, o que lhe pode permitir seguir nas suas escolhas.

A par dessa trágica situação, os PCN, lançados há doze anos, respaldam uma concepção de linguagem coadunada com as modernas teorias da área da linguagem. O cerne da proposta dos Parâmetros Curriculares Nacionais de língua portuguesa visa à garantia de formas de aprendizagem da leitura e da escrita para todos os estudantes. O que isto significa? 


\section{A importância da área da linguagem para a formação básica do estudante}

No mundo contemporâneo, caracterizado por diversidades de linguagem, o uso adequado e eficiente do domínio das diferentes formas de comunicação é cada vez mais necessário. Esta diversidade pressupõe a interação face a face, a interação por meio do papel e da comunicação eletrônica. Estas formas de interação não se contrapõem. Na verdade, são linguagens que se entrecruzam e se complementam, se efetivando em diferentes gêneros e suportes, tais como os quadrinhos, a publicidade, a informática, a literatura, a pintura, entre outras tantas e tantas formas. Por isso, constitui-se em grande diferença na formação de um estudante, hoje, o domínio das distintas formas de linguagem. Dominar a linguagem significa estar mais preparado para interagir com outras pessoas, o que implica ter a possibilidade de influenciar em seu modo de agir e pensar, e, da mesma forma, ser influenciado (ou se deixar influenciar), por meio da linguagem, por nossos interlocutores.

Evidentemente, não há uma única concepção de linguagem. As diferentes concepções coexistentes são frutos das distintas posições e discussões de filósofos, linguistas, semiologistas, antropologistas e teóricos do conhecimento. Geraldi (2003: p: 18), ao discutir as questões sobre o ensino de língua nas escolas, esclarece que falar sobre linguagem é fundamental no desenvolvimento do sujeito e "que ela é condição sine qua non na apreensão de conceitos que permitem aos sujeitos compreender o mundo e nele agir..." Essa visão explicita a importância de pensar o ensino de língua portuguesa à luz da linguagem e pensá-lo como processo interlocutivo. Nesta mesma perspectiva, Koch (2002) postula um conceito de língua como lugar de interação em que o sujeito tem um papel ativo nessa atividade. $O$ texto é o lugar, o meio em que a interação é realizada. É a partir das pistas linguísticas construídas nas suas redes textuais que os sentidos serão depreendidos. Por isso, o texto é uma atividade de interação comunicativa, "um fenômeno cultural, histórico, social e cognitivo que varia ao longo do tempo e de acordo com os falantes" (MARCUSCHI, 2002. p. 19-36). Ainda, segundo Koch (2004: p.12), a Linguística textual concebe o texto em diferentes perspectivas, a saber: 
1. Texto como frase complexa ou signo linguístico mais alto na hierarquia do sistema linguístico (concepção de base gramatical)

2. Texto como signo complexo (concepção de base semiótica)

3. Texto como ato de fala (concepção de base pragmática)

4. Texto como processo que mobiliza operações e processos cognitivos (concepção de base cognitivista)

5. Texto como lugar de interação entre atores sociais e de construção interacional de sentidos (concepção de base sociocognitiva-interacional)

Considerando as concepções de base (sócio)cognitivista, acredita-se em um processo educacional que interpreta os indivíduos como sujeitos sociais, que não são prontos, mas que se (re)constroem discursivamente. Por essa razão, a escola tem função primordial de ampliar o domínio linguístico do aluno, para que seja capaz de participar ativamente da sociedade em que está inserido. Ao se conceber a língua como forma de interação, aceitamos (ou reconhecemos) a diversidade textual que se manifesta na sociedade e confronta as diferentes formas textuais no tocante à organização, às finalidades, às dificuldades e às facilidades de produção. É, enfim, compreender e considerar as etapas de processamento e de realização que as envolve.

Nessa perspectiva, a linguagem que utilizamos não transmite, apenas, nossas ideias. As palavras e as expressões, bem como as estruturas sintáticas que selecionamos, ao falar e ao escrever, refletem e demonstram quem somos: de que região somos procedentes, nosso nível de escolarização, nosso nível social, nossos valores, crenças e, por que não dizer, ideologias. Por isso, a língua é um poderoso instrumento de ação social. Ela pode tanto facilitar quanto dificultar o nosso relacionamento com as pessoas e com a sociedade em geral.

Logo, o ensino da língua culta na escola representa mais uma forma disponível ao falante para agir em relação ao outro, nosso interlocutor. O domínio da norma culta, somado ao domínio de outras variedades linguísticas - da família, de nossa comunidade, por exemplo - torna o falante mais preparado para usar a língua, de modo adequado nas diferentes situações sociais de que participamos. Esta é uma função essencial da escola, já que é o lugar, por excelência, de formalização do conhecimento. 
Toda a vez que interagimos com outras pessoas por meio da linguagem, há uma intenção de modificar o pensamento, o comportamento de nossos interlocutores. O sucesso de nossas interações verbais depende muito mais de nossa capacidade de lidar, interpretar, ler as intencionalidades discursivas. Por isso, a situação de comunicação pressupõe uma rede que auxilia na construção de sentidos, a saber: os papéis sociais que os interlocutores desempenham, a intenção do interlocutor, o conhecimento de mundo dos interlocutores, as circunstâncias históricas e sociais em que ocorre a comunicação. Para exercermos com eficiência este papel, é fundamental que sejamos leitores proficientes. Esta é a função primordial da escola: desenvolver as competências linguístico-discursivas do falante/ leitor/ produtor de texto.

Algumas condições são necessárias para o desenvolvimento desse leitor proficiente. Considerando que a língua só existe na interação entre os interlocutores, deve-se estudar nas aulas de língua portuguesa a linguagem, o discurso - atividade comunicativa capaz de gerar sentido entre interlocutores, que, além dos enunciados verbais, engloba outros elementos do processo comunicativo que têm participação na construção do sentido do texto, entendido como sua materialização. Portanto, a prática de sala de aula deve estar centrada no texto, tendo como objetivo a ampliação da experiência leitora do estudante. $\mathrm{O}$ que vai diferenciar a abordagem textual nos diferentes anos de escolaridade é a diversidade dos gêneros oferecidos, os modos de organização destes textos, com seus diferentes propósitos comunicativos.

A consciência, por exemplo, das diferenças entre os fatos reais e os fatos do texto, a verossimilhança, constitui condição para tal aprimoramento discursivo. A diversidade textual impõe-se no uso dos recursos da língua que compõem um determinado gênero. É neste sentido que a complexidade da tarefa de aprendizado da leitura e da escrita está pautada: na escolha dos textos, suas finalidades e uso dos recursos. O leitor deve ser conscientizado a ler, entender as informações contidas no texto, sabendo reconhecer o "peso" diferente dado às ideias no interior do texto. Quanto mais proficiência leitora o aluno tiver, mais competente será para estabelecer as relações de sentidos entre parágrafos, dentro dos parágrafos e entre textos, por 
exemplo, percebendo as diferentes vozes existentes, a função destas no texto, e o lugar de onde cada uma delas é proferida.

É preciso enfatizar que, nos níveis mais altos de proficiência, cabe ao leitor - aluno/ professor - o constante aprimoramento por meio do desenvolvimento de habilidades, sempre voltadas para as diferenças semântico-discursivas. Trata-se de um trabalho sem fim, ou seja, de constante aprimoramento. Cabe à escola municiar o aluno, que deve continuar tal aprimoramento para além da instituição, por natureza, responsável pelo ensino formal.

\section{Os diferentes tipos de saberes na construção da linguagem: alguns pressupostos}

Há muitos estudos que buscam discutir a escolarização, a exemplo de Soares $(2004,2005)$ e Kleiman $(1998,2006)$. Esses estudos têm apresentado nas mesmas condições de igualdade o denominado saber formal, que diz respeito aos conhecimentos aprendidos na escola; e o saber cotidiano, aquele que qualquer sujeito inserido no meio social tem ou desenvolve. Na visão dos estudiosos, esses conhecimentos se diferenciam basicamente por aspectos contextuais. De um lado, há saberes que adquirimos somente com a formalização da escola, tais como os cálculos da química e da matemática, o domínio da escrita em língua materna; de outro, há saberes específicos da vida cotidiana, considerados como saberes informais, tais como a realização de uma receita de doce, de pequenos consertos, do ato de jogar bola ou de soltar pipa. Trata-se de saberes que são igualmente importantes e constituem o repertório de conhecimentos do cidadão, os denominados conhecimentos de mundo e enciclopédico.

Entretanto, na perspectiva do processo ensinar-aprender, considerando uma visão cognitivista, há saberes que apenas se distinguem pelo enquadramento que é dado àquele conhecimento. Isso significa dizer que a notícia de jornal lida na rua e em casa, e que também pode ser lida na escola, se constitui em atos de interação diferentes, dada a intenção comunicativa que os interlocutores têm nas três diferentes situações de leitura do mesmo gênero. A leitura da notícia realizada na escola passa a ser de outra natureza, porque se deseja não só 
saber sobre a informação, mas também porque essa leitura tem como objetivo uma perspectiva de análise e de avaliação, por exemplo, se ocorrida em uma atividade de aula de história ou de língua (KLEIMAN, 2006).

As atividades desenvolvidas na escola devem ter um objetivo maior, qual seja de desenvolvimento do conhecimento, de diferentes competências. Pode-se afirmar, em consonância com vários estudiosos (SCRIBNER \& COLE, 1981; STREET, 1984; FAIRCLOUGH, 2002; SOARES, 2004; KLEIMAN, 2006), que nenhum saber se torna mais científico, apenas, porque é transmitido pela escola. Significa dizer que os saberes ensinados na formalização da escola não requerem um processamento cognitivo superior. Trata-se, na verdade, de uma questão de enquadramento cognitivo para os fins específicos que a escola deseja atingir. Nesse sentido, é crucial a escola (re)conhecer o que precisa, o que deseja ensinar e como fazê-lo, para que fazê-lo, tendo como pressuposto, para todas as áreas de conhecimento, o desenvolvimento da linguagem como eixo cognitivo necessário para o desenvolvimento humano.

Para a ampliação de um trabalho voltado para o desenvolvimento de competências discursivas do aluno, especialmente no que tange a sua competência leitora/escrita, o professor deve lançar-se ao desafio de um trabalho com gêneros textuais diversificados, bem como com diferentes tipologias de texto, a fim de que o aluno compreenda as variedades de situações comunicativas que um texto, oral ou escrito, verbal ou não-verbal, possa representar. As atividades de linguagem em sala de aula precisam fazer sentido e não funcionarem, apenas, como objeto de análise metalinguística. Além disso, se entendermos a linguagem como uma condição humana, esse processo de aprendizagem, de desenvolvimento da capacidade discursiva do estudante, deverá ocorrer nos diferentes componentes curriculares da escola, já que leitura e escrita perpassam todas as áreas de conhecimento. Com tal perspectiva metodológica, baseada em concepção mais ampla de linguagem, a escola atingirá um dos aspectos presentes nos PCN: formar um aluno reflexivo, crítico, criativo e transformador, tornando-o capaz, como dito anteriormente, de participar ativamente na (da) sociedade em que está inserido. 
Logo, pode-se vislumbrar uma concepção de aprendizado distanciada de um sujeito como ser passivo e um depósito de informações, cujo conceito consequente é de ensinar, apenas, como enformar. Paulo Freire (1996: p.28-29) afirma que o educador democrático não pode negar a si mesmo o dever de, na sua prática docente, reforçar a capacidade crítica do educando, sua curiosidade, sua insubmissão. Uma de suas tarefas primordiais é trabalhar com os educandos a rigorosidade metódica com que devem se aproximar dos objetos cognoscíveis.

Embora de perspectiva diferente do postulado por Freire, Perini (1997, p. 24) se coaduna à visão freiriana, ao postular que

Uma língua é muito mais do que uma lista de nomes para coisas - é, de certa forma, um sistema de organização do mundo, um dos instrumentos que nos servem para compreender a imensa complexidade da realidade que nos cerca.

Ambos os autores trazem à baila em seus postulados a relação linguagem/ compreensão do mundo. Por isso, pode-se afirmar que a rigorosidade metódica, (cf. § anterior) está dissociada do discurso bancário (cf. FREIRE, 1983, p.66), meramente transferidor do perfil do objeto ou do conteúdo.

Se a compreensão das coisas do mundo passa pela compreensão da linguagem, estudar a língua materna, no nosso caso, a língua portuguesa, portanto, é ter a oportunidade de entender um modo de organização não só do mundo, como também do pensamento. Por isso, mesmo como falantes da língua portuguesa, é condição precípua termos a oportunidade de estudar suas estruturas, pois nesse movimento estamos estudando o processamento ou a construção da mente humana, na forma de recorte e de organização da realidade, o que efetivamente nos tornará capazes de compreender aquilo que nos cerca. Entender o ensino de língua portuguesa nessa concepção é entender a língua como forma de interação. A língua só ocorre por meio do discurso; este se concretiza por meio dos diferentes textos que circulam na sociedade. Por isso, a premissa básica para o ensino de língua portuguesa nos diferentes níveis de escolarização é o trabalho com o texto nas suas diferentes possibilidades. 
A prática de leitura é de fundamental importância para que o estudante possa compreender o discurso do outro e interpretá-lo. Uma perspectiva de análise na leitura de textos a se ensinar nas salas de aula é distinguir que elementos da língua o produtor do texto lança mão para dizer o que quer dizer. Neste sentido, estamos ensinando gramática, ao entendermos, por exemplo, o efeito de sentidos que o uso de um adjetivo (pode) causa(r) no texto. Algum falante pode, de fato, entender que bonito e lindo têm o mesmo significado? É claro que não, embora saibamos que esses dois adjetivos estão no mesmo campo semântico. Entretanto, a escolha de um ou outro termo indica efeito de sentido específico e determinada intenção de dizer que precisa ser reconhecida/entendida no processo de interação. Considerar o texto como ponto de partida nas aulas de Língua Portuguesa é necessário, pois se pode mostrar ao estudante a intenção comunicativa do produtor do texto na escolha desta ou daquela estrutura morfossintática.

Por outro lado, dadas as peculiaridades de nossa área de estudos, a área de linguagem, não só devemos entender o que o outro diz, mas devemos nos fazer entender também. Devemos saber fazer as escolhas - como produtores de textos - dentro das possibilidades da língua, que permitam dizer aquilo que queremos dizer. Por isso, precisamos produzir textos nas atividades didáticas que compõem as aulas de língua portuguesa. As situações de escrita devem também ser contextualizadas, para que tenham sentido, ou seja, para que o estudante entenda o motivo daquela atividade didática, daquela produção de texto, para que o estudante - produtor do texto - possa, efetivamente, entender para quem fala, por que fala. A Figura 1 retrata a relação dessas práticas na aula de língua portuguesa, considerando que as mesmas confluem para a construção do entendimento do texto, sendo leitura/escrita, verso e reverso desse processo de conhecimento: 


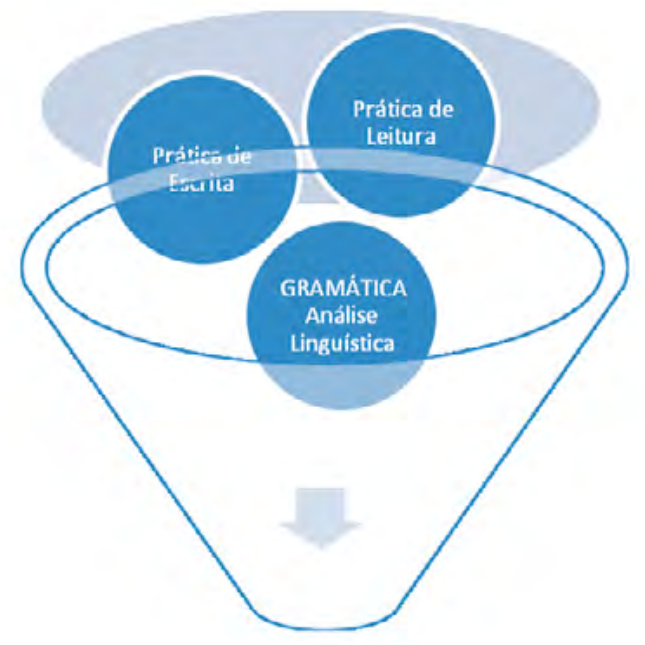

Figura1: A relação escrita/leitura e análise linguística

Pode-se afirmar que não é possível estudar a língua - ler e escrever textos - sem que estejamos lidando com a gramática. Ocorre que a gramática deixa de ser vista como um aglomerado de listas de pura decoreba, sem sentido, para estar, efetivamente, a serviço do texto. Fala-se, por conseguinte, de uma estreita relação entre texto/gramática, deixando de considerar esta gramática, apenas, como uma listagem de nomes. Ensinar a gramática da língua é entender seus diferentes meios de expressão de sentido, os processos sintáticos e morfológicos materializados em textos.

Ao se pensar nesses possíveis contextos, uma característica que pode ser considerada um entrave para o estudo da língua na perspectiva apresentada é desconsiderar que a referência de língua do estudante, quando chega à escola, é a modalidade oral. As práticas escolares precisam considerar tal condição, digamos, natural do falante. O que ocorre, por vezes, é a desconsideração da escola pelo registro linguístico que o aluno traz, a modalidade oral de nossa língua, em suas diferentes variações. É preciso que os estudantes nos diferentes níveis de escolaridade conheçam as estruturas da língua escrita, para que possam dominá-la. Para tanto, é preciso entender a existência de características peculiares destas duas modalidades, quais sejam: i) a língua escrita mantém a separação entre as palavras, diferentemente da língua oral, 
cuja característica básica é um continuum; ii) a língua escrita pressupõe o uso da pontuação; a língua oral, a entoação; é preciso que o estudante perceba que o ritmo, por exemplo, não é o mesmo entre "o como se diz" e "o como se escreve", ou seja, o estudante deve ter consciência que a pontuação não se constitui em transcrição da forma como falamos; iii) a forma que pronunciamos as palavras não é de todo correspondente a seu registro escrito; tal consideração, sem dúvida, traz produtiva reflexão sobre as questões ortográficas da língua; iv) a língua escrita tem como natureza a necessidade de maior/ mais contextualização, diferentemente da língua oral. Esta é uma prática de reflexão necessária sobre o texto escrito, para que o estudante tome consciência das diferenças entre as modalidades e possa aprender as estratégias a serem utilizadas, de acordo com seus propósitos comunicativos, com o contexto de uso, a fim de que se possa fazer entender e ser entendido.

Essas são, apenas, algumas das características a serem levadas em conta, ao se tratar das características das duas modalidades da língua. O estudante deve entender esses diferentes processos, tomar consciência do continuuum entre fala e escrita, partindo do estudo e da análise de gêneros textuais típicos da oralidade, típicos da escrita, a fim de dominar estes diferentes usos. Vale lembrar que estudar tais recursos, também é estudar gramática. Entretanto, não são saberes que se constroem rapidamente. Devem ser considerados quando do planejamento das aulas de língua portuguesa nos diferentes anos de escolaridade, ao longo do ensino básico, em sucessivas etapas de análise, reflexão linguístico-textual.

\section{O que diferencia o ensino de Língua Portuguesa ao longo da escolarização?}

A diferença do ensinar português nos distintos anos de escolarização não está em se ensinar mais ou menos nomenclatura gramatical, como por exemplo, identificar as dez classes de palavras e todas as funções sintáticas ao final do nono ano, discussão que tomou conta de várias reflexões acerca do ensino de língua portuguesa. O que diferencia a tarefa de ensino de leitura/escrita, do aprendizado da língua portuguesa, ao longo dos anos de escolarização, é a complexidade do texto, a complexidade na abordagem textual, marcada pela temática 
e pelas estruturas gramaticais que estruturam um dado texto. Por isso, por exemplo, no nono ano do Ensino Fundamental, para estudantes que já tenham uma experiência leitora, se pode indicar os romances da literatura brasileira. Nas séries iniciais desse mesmo nível, é possível se lançar mão de textos da literatura infantil, tão representativa em nossa língua: os contos de fadas, as lendas, as histórias em quadrinhos, as fábulas, além de textos de Monteiro Lobato, Ana Maria Machado, Ligia Bojunga, Ziraldo, para citar alguns dos escritores.

Importante, porém, é entender que o aumento da ora denominada complexidade da tarefa está vinculado à exposição ininterrupta de textos, de leitura crítica, fluida, ao longo da escolaridade desde o primeiro momento da escolarização. Por isso, é importante ler, permanentemente, em sala de aula, integrando os eixos conceptuais, conforme ilustra a Figura 2:

LINGUAGEM/INTERAÇÃO

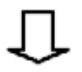

LÍNGUA / PROCESSO/FENÔMENO

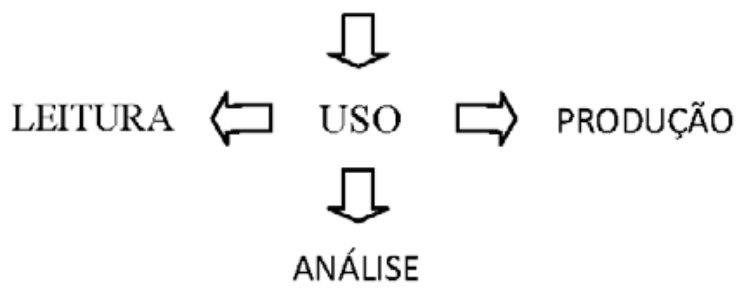

Figura 2: Eixos Conceptuais

Esses eixos nos remetem à intrínseca relação de leitura/ escrita/análise linguística, privilegiando o uso da língua como componente central do ensino. Tal uso se revela na produção de sentidos, concretizada na leitura por meio da própria construção destes sentidos como sujeito-autor do processo de interação, que só pode ocorrer no pleno domínio da língua.

O modelo de ensino predominante, em geral, é de uma escola que, ao desenvolver as tarefas de produção de texto, o faz em uma estrutura e em um modelo repetitivos, que não abarcam as necessidades de produção de textos em diferentes situações de comunicação. O exercício de escrita na escola restringe-se, em geral, a uma tarefa escolarizada, cuja forma predominante é a escrita de textos narrativos nos diferentes 
anos de escolarização que compõem o Ensino Fundamental e a produção de textos dissertativos no Ensino Médio, com vistas às provas de seleção discentes para ingresso no Ensino Superior. A metodologia de ensino está restrita à tipologia e não aos gêneros propriamente. Na perspectiva ora apresentada, abraçar a metodologia, partindo de gêneros textuais, significa reconhecer as regularidades discursivas em uso, peculiares a cada gênero, propondo análise crítica desses usos.

O ensino da língua/linguagem deve estar circunscrito à necessidade de desenvolvimento do exercício pleno da cidadania. É preciso que cada cidadão possa se sentir capaz de escrever, falar, ouvir e ler todos os gêneros e tipos adequados a cada situação vivida, na utilização das diferentes linguagens, tanto para a expressão do pensamento e das emoções quanto para a organização e análise das informações recebidas. Assim, percebemos que não há sentido em se fazer um escalonamento entre as ações de grafar e redigir, alfabetizar e letrar, por exemplo. O educando, ao nascer, já participa do mundo letrado e sobre ele constrói diferentes conhecimentos. Uma criança, ao ditar para o colega ou para a professora uma história que conhece de cor, já está redigindo um texto, com coerência e coesão. Logo, as referidas ações devem ser vistas como componentes do processo de aprendizagem da leitura e da escrita, utilizadas concomitantemente, já que estamos considerando o conceito de leitura e escrita como práticas sociais.

Os Parâmetros Curriculares Nacionais preconizam que o ensino de Língua Portuguesa seja baseado na organização de atividades que levem o aluno a desenvolver a expressão oral e escrita, bem como a capacidade de compreensão, em situações de interação, valorizando o contexto da produção, além das dimensões semântica e gramatical. Essas atividades, do ponto de vista cognitivo, não se realizam pontualmente. São representadas por diferentes níveis, a que se podem chamar de habilidades, cujo conjunto bem desenvolvido leva à proficiência em leitura e escrita.

\section{Considerações finais}

Não há intenção de prescrever comportamentos metodológicos para o ensino produtivo de língua portuguesa na escola básica. No entanto, ao propor reflexões sobre o tri- 
buto da área de linguagem para o ensino básico, não se pode deixar de elencar atitudes linguístico-discursivas que devem orientar a prática docente nos diferentes anos de escolaridade e as matrizes curriculares da escola básica. A aula deve estar planejada em torno de textos ininterrupta e continuamente. Deve-se priorizar o uso da diversidade de gêneros textuais e diferentes tipologias, para que o aluno compreenda as variedades de situações comunicativas que um texto, oral ou escrito, verbal ou não verbal, possa representar. Deve-se conscientizar o estudante do uso social da leitura e da escrita, desenvolvendo suas práticas leitoras nas diferentes situações de comunicação em que pode estar inserido. Sabe-se que essas situações são simuladas em sala de aula. Entretanto, quanto mais próximas estiverem da realidade de uso da língua, mais profícuas serão as discussões relativas aos recursos linguísticos pertinentes aos diferentes gêneros.

Quanto aos procedimentos de leitura mais adequados nesta concepção para a abordagem de um texto em aula de língua, considera-se essencial o levantamento de hipóteses. Deve-se proceder à leitura de reconhecimento do texto, que pode ser individual, coletiva, em voz alta, em voz baixa, em duplas. O levantamento de hipóteses deve estar calcado nos elementos linguísticos utilizados pelo produtor do texto na elaboração de seu projeto de dizer, o que faz chegar ao processo de inferência das informações implícitas no texto, no confronto das explicitudes e implicitudes de um texto com suas ancoragens textuais.

O estudo deve ser ampliado, propiciando a análise comparativa de diferentes textos, quer em paródias, quer em abordagens temáticas diferenciadas (opiniões divergentes, por exemplo). É profícua a abordagem da estrutura do gênero em estudo, o que permitirá ao estudante, em fase de aquisição da língua escrita, entender, por exemplo, o que diferencia uma lenda de um conto de fadas, apesar de ambos os gêneros pertencerem ao tipo de texto narrativo. A vinculação das propostas de produção de textos aos gêneros estudados indica o quão importante é trabalhar com os modelos textuais para o domínio de suas estruturas. A prática da escrita deve passar, necessariamente, pela escrita-reescrita do texto, incluindo a avaliação crítica não só pelo professor, mas também pelos colegas de classe, atores do processo de interação da linguagem. 
A organização didática deve prever sempre uma progressão das atividades em aula, concebendo a prática discursiva da oralidade, da leitura, da compreensão do que está sendo lido em perspectiva microtextual - em nível da frase, da oração, do período e do parágrafo, estabelecendo as relações de sentido - e em perspectiva macrotextual - que revela o texto pertencer a um determinado gênero. As duas perspectivas são entendidas como abordagem gramatical, não da prescrição, mas do uso da língua e do efeito de sentido desse uso. Esse elenco de atividades tem como fundamentação e suporte as teorias desenvolvidas na área dos estudos linguísticos.

Por fim, a escrita dos estudantes deve ser também objeto de estudo na aula de língua materna. Cabe aos professores analisar os erros existentes, para conscientizar o estudante, tanto ortográfica quanto textualmente, do que pode ser modificado em sua escrita, assim como acontece conosco, mesmo sendo produtores de textos proficientes, quando escrevemos.

Enfatiza-se que o objetivo de desenvolver o raciocínio, a capacidade de pensar, de analisar criticamente deve extrapolar o ensino de língua materna, por ser amplo. Caracteriza-se como uma busca constante do desenvolvimento de habilidades do aluno que, diante de fatos e fenômenos da vida, observa, formula hipóteses e busca comprovação ou não dessas. Assim deve ser a função da escola: dar caráter científico à sua perspectiva disciplinar. Trata-se de enfatizar esse objetivo como intrínseco às metas específicas do ensino de língua materna, pois seu objeto de estudo, o material linguístico, é muito amplo e perpassa as demais disciplinas

\section{REFERÊNCIAS}

FAIRCLOUGH, N. Analysing discourse: textual analysis for social research. London: Routledge, 2002.

FAUCONNIER, G. Mental Spaces: aspects of meaning construction in natural language. New York: Cambridge University Press, 1994 [ $p 1985]$.

FOUCAULT, M. A arqueologia do saber. 3.ed. Rio de Janeiro: R.J.. Forense- Universitária, 1987. ( tradução)

FREIRE, Paulo. Pedagogia da Autonomia. Saberes necessários à prática educativa. São Paulo: Paz e Terra, 1996. 
FREIRE, Paulo. Pedagogia do Oprimido. São Paulo: Paz e Terra, 1987.

GERALDI, J. W. Portos de Passagem. 4.ed. São Paulo: Martins Fontes, 2003.

KLEIMAN, A. Texto e leitor: aspectos cognitivos da leitura. 4. ed. Campinas: Pontes, [1995] 2006.

Schooling literacy and social change: elements for a critical approach do the study of literacy. In: OLIVEIRA, M. K., VALSINER, J. (eds.). Literacy in human development. Stanford, CT: Ablex Publishing Corporation. 1998. p. 183-226.

KOCH, I. G. V.. Desvendando os segredos do texto. São Paulo: Cortez Editora, 2002.

Introdução à Lingüística Textual. São Paulo: Martins Fontes, 2004.

MARCUSCHI, L. A "Gêneros textuais: definição e funcionalidade" in. DIONÍSIO, ET AL. Gêneros textuais e ensino. Rio de Janeiro: Lucerna, 2002.

PERINI, Mario A. Sofrendo a gramática: a matéria que ninguém aprende. In: . Sofrendo a gramática: Ensaios sobre a linguagem. $3^{\text {a }}$ ed. São Paulo: Ática, 1997.

SCRIBNER, S., COLE, M. The psychology of literacy. Harvard: University Press, 1981.

SOARES, M. Linguagem e escola: uma perspectiva social. 17. ed. São Paulo: Ática, 2005. Letramento e escolarização. In: RIBEIRO, V. M. (org.). Letramento no Brasil. São Paulo: Global/Instituto Paulo Montenegro, 2004. p. 89-113.

STREET, Brian V. Literacy in theory and Pratice. Cambridge: University Press, 1984. 


\section{Abstract \\ The challenges to the language area}

Considering the worrying levels of brazilian student's proficiency development, that illustrates Brazil's educational failure, this paper aims at thinking about the importance of the language to the students' basic development. We claim that dominating language means to be prepared to interact to people, which implies to have the possibility to influence people in the way they act and think about the others. In the (social)cognitivist perspective, we believe in an educational process which looks straight at each one as a social subject. In this way, people are not ready, but are (re) constructions in the discursive practices. By the way, the school's practices have as main function to develop the linguistic abilities, considering the different discourse genres in this owner organization and communicative proposes. The consequence is to become the student able to participate of the society actively when they know to read, to write and the discourse analyses, which includes the perspective of grammar's language. It means that the language is the greater linguistic heritage which must be investigated not only in mother language classes, but also in other subjects, stimulating the scientific approach, a tribute of the linguistic area.

Keywords: Language. Teaching. Different genres. Proficiency development. 